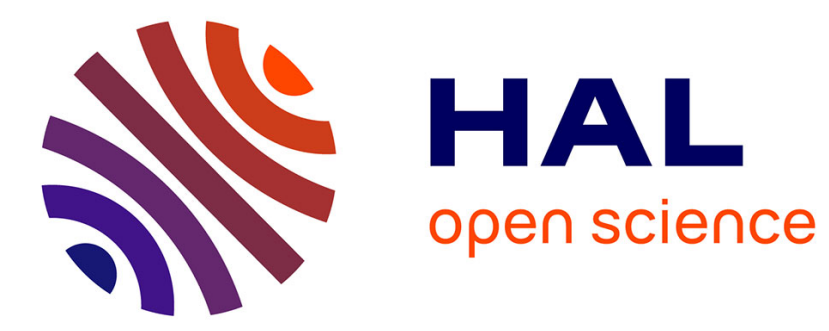

\title{
Multidecadal Trajectory of Riverine Nitrogen and Phosphorus Dynamics in Rural Catchments
}

Rémi Dupas, Camille Minaudo, Gérard Gruau, Laurent Ruiz, Chantal Gascuel

\section{To cite this version:}

Rémi Dupas, Camille Minaudo, Gérard Gruau, Laurent Ruiz, Chantal Gascuel. Multidecadal Trajectory of Riverine Nitrogen and Phosphorus Dynamics in Rural Catchments. Water Resources Research, 2018, 54 (8), pp.5327-5340. 10.1029/2018wr022905 . insu-01857435

\section{HAL Id: insu-01857435 \\ https://hal-insu.archives-ouvertes.fr/insu-01857435}

Submitted on 16 Aug 2018

HAL is a multi-disciplinary open access archive for the deposit and dissemination of scientific research documents, whether they are published or not. The documents may come from teaching and research institutions in France or abroad, or from public or private research centers.
L'archive ouverte pluridisciplinaire HAL, est destinée au dépôt et à la diffusion de documents scientifiques de niveau recherche, publiés ou non, émanant des établissements d'enseignement et de recherche français ou étrangers, des laboratoires publics ou privés. 


\section{Water Resources Research}

\section{RESEARCH ARTICLE}

10.1029/2018WR022905

\section{Special Section: \\ Dynamics in Intensively Managed Landscapes: Water Sediment, Nutrient, Carbon, and Ecohydrology}

Key Points:

- Long-term $\mathrm{N}$ and $\mathrm{P}$ trends disentangled from effect of interannual climate variability

- $\mathrm{N}$ and $\mathrm{P}$ trends responded to changes in agricultural $\mathrm{N}$ surplus and point source $P$ inputs, respectively

- Time lags in $\mathrm{N}$ load response to variations in inputs influenced by legacy storage in catchments

Supporting Information:

- Supporting Information S1

Correspondence to:

R. Dupas,

remi.dupas@inra.fr

Citation:

Dupas, R., Minaudo, C., Gruau, G., Ruiz, L., \& Gascuel-Odoux, C. (2018).

Multidecadal trajectory of riverine nitrogen and phosphorus dynamics in rural catchments. Water Resources Research, 54. https://doi.org/10.1029/ 2018WR022905

Received 8 MAR 2018

Accepted 8 JUL 2018

Accepted article online 17 JUL 2018

C2018. American Geophysical Union. All Rights Reserved.

\section{Multidecadal Trajectory of Riverine Nitrogen and Phosphorus Dynamics in Rural Catchments}

\author{
Rémi Dupas $^{1}$ iD, Camille Minaudo ${ }^{2}$ iD, Gérard Gruau ${ }^{3}$, Laurent Ruiz ${ }^{1}$ iD, and Chantal Gascuel-Odoux ${ }^{1}$ \\ ${ }^{1}$ INRA, UMR 1069 SAS, Rennes, France, ${ }^{2}$ E.A. 6293 GeoHydrosystemes COntinentaux, University Francois Rabelais, Tours, \\ France, ${ }^{3}$ CNRS, UMR 6118 Géosciences Rennes, Rennes, France
}

\section{Introduction}

Human activities have substantially altered riverine exports of nitrogen $(N)$ and phosphorus $(P)$ in the Anthropocene (Galloway et al., 2004; Seitzinger et al., 2010; Worrall et al., 2016), causing major alterations of freshwater and marine ecosystems worldwide (Sardans et al., 2012; Steffen et al., 2015). Documenting anthropogenic alterations of nutrient cycles in aquatic ecosystems is a challenge as industrialization in western countries began in the eighteenth century and agricultural intensification in the midtwentieth century, while river monitoring became widespread only since the 1990s, with few noticeable exceptions of multidecadal data sets starting earlier (Billen et al., 2007; Howden et al., 2010; Kopacek et al., 2017; Pinay et al., 2017; Romero et al., 2016; Stets et al., 2015; Viaroli et al., 2018; Worrall et al., 2016).

Where multidecadal water quality data sets are available, even at low sampling frequencies (Burt et al., 2011), long-term trends can be interpreted in relation to land use, land management, and climate changes in catchments. Changes can be sudden or more gradual: for example, Howden et al. (2010) interpreted a sudden increase in nitrate concentration in the 1970s as the consequence of massive grassland plowing in the post second world war in the Thames basin, United Kingdom. Sharp shifts in phosphate and nitrate concentrations in the late 1990s to early 2000s have been interpreted by Romero et al. (2016) as the result of the upgrading of a large wastewater treatment plant in the Seine basin, France. Responses to diffuse emissions resulting from evolving land management systems are usually more gradual due to the potentially long transit time of nutrients in catchments (Fovet et al., 2015; Hrachowitz et al., 2016; Vero et al., 2017) and to interaction of nutrient cycling with interannual climate variations (Gascuel-Odoux et al., 2010; Mellander et al., 2018). Disentangling the influence of interannual climate variations from long-term changes in land use and management on water quality is a challenge in many areas (Burt et al., 2011). For example, Dupas et al. (2016) analyzed a 32-year nitrate time series from a catchment in eastern Germany and found that, despite this catchment having experienced major changes in land use and management during the study period, interannual climate variability still explained most of the variability in nitrate concentrations.

The long-term evolution of a catchment's water quality under changing external forcings, termed hereafter trajectory, does affect not only mean annual concentrations and fluxes but also intraannual variations. Seasonal variations in nutrient concentrations are often interpreted in terms of (i) dominant point versus diffuse sources (Jarvie et al., 2010; Withers et al., 2014); (ii) spatial distribution of nutrient sources in catchment, 


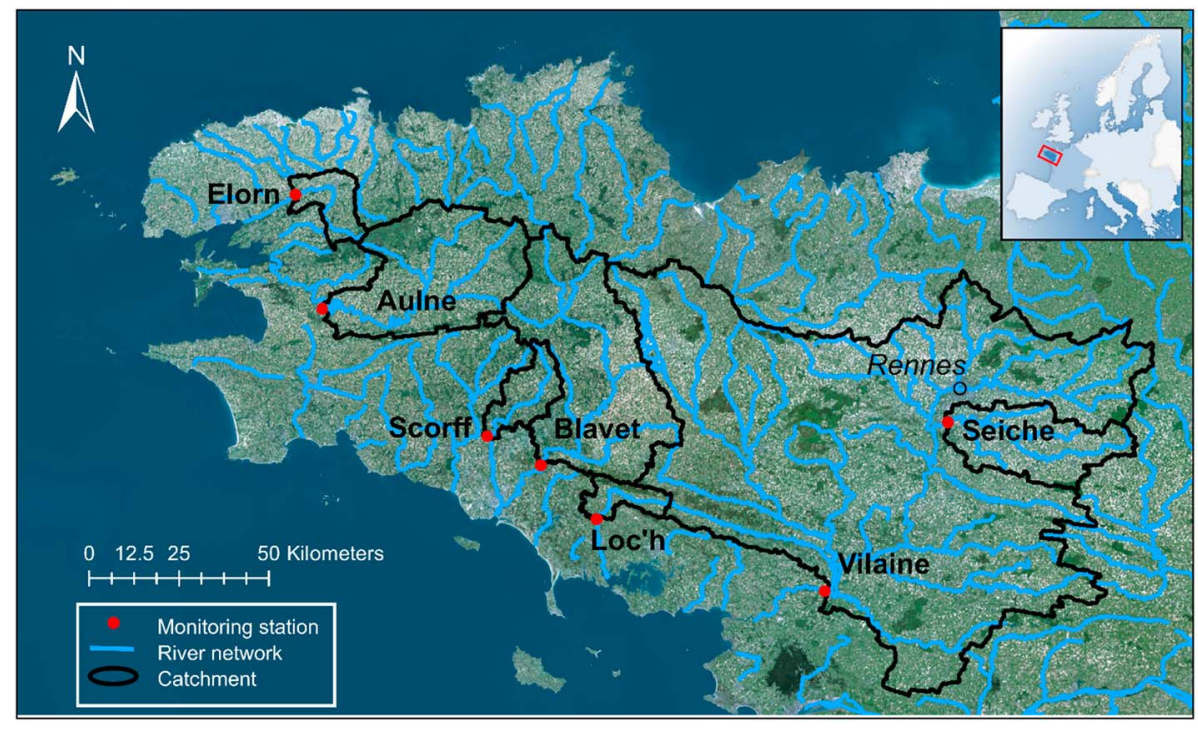

Figure 1. Localization of the study catchments.

vertically (Abbott et al., 2018; Dupas et al., 2016; Musolff et al., 2016) or laterally (Aubert et al., 2013; Musolff et al., 2017); and (iii) temperature-dependent release and retention mechanisms, within soils (Aubert et al., 2013; Dupas, Musolff, et al., 2017) or the river network (Mulholland et al., 2008; Rode et al., 2016). Worrall et al. (2015) observed that different components of the Thames nitrate time series (e.g., annual maxima and minima) had different responses to land use and climate drivers, and that the amplitude and phase of seasonal variations varied over a 130-year period. Similarly, Minaudo et al. (2015) observed that phosphate seasonal variations in the Loire river (maxima during summer in the upper Loire and during winter in the lower Loire) decreased as a result of decreasing point source discharges over a 30-year period.

For the most part, the longest concentration time series available worldwide have been acquired in large rivers such as the Thames (Worrall et al., 2015), the Rhine and Danube (Hartmann et al., 2007), the Loire (Minaudo et al., 2015), the Seine (Romero et al., 2016), the Po (Viaroli et al., 2018), the Mississippi, and the Susquehanna (Van Meter et al., 2017) with catchment areas $>10,000 \mathrm{~km}^{2}$. However, such large areas often comprise several landscape types, with potentially different nutrient trajectories that cannot be deciphered with observations only at the outlet of large catchments. Moreover, they often encompass large urban areas, hence with point source pollution potentially masking the influence of changing agricultural land use and management (Bishop et al., 2008; Dupas, Musolff, et al., 2017).

In this context, few opportunities exist to study multidecadal trajectories of $\mathrm{N}$ and $\mathrm{P}$ dynamics in rural catchments of relatively small size. The Brittany region, a rural peninsula of western France, has experienced a relatively late but rapid development of intensive agriculture since the 1960s and ambitious programs of measures to improve water quality since the 1990s (Dupas et al., 2013; Gascuel-Odoux et al., 2010). Because Brittany is a peninsula with a high density of rivers, it comprises several coastal catchments of relatively small size $\left(<5,000 \mathrm{~km}^{2}\right)$, among which seven have been monitored since the 1970s for discharge and the water quality parameters nitrate- $\mathrm{N}$, soluble reactive phosphorus (SRP), and total phosphorus (TP). Here we analyze these seven multiparameter time series with the objectives to investigate (i) long-term multidecadal trajectory of $\mathrm{N}$ and $\mathrm{P}$ concentrations in relation to the history of diffuse and point source pressures, (ii) medium-term interannual variations in relation to climate variability, and (iii) seasonal variations (and their long-term evolution) in relation to catchment properties and history.

\section{Materials and Methods}

\subsection{Study Area}

Brittany is a $27,000-\mathrm{km}^{2}$ region located in western France that contains a large number of small coastal rivers (Figure 1). Brittany belongs to the Armorican massif, composed of metamorphic and igneous rocks (granite, 
schist, micaschist). The climate is temperate oceanic, with a mean annual temperature of $11.2^{\circ} \mathrm{C}$ and mean annual rainfall ranging from $1,400 \mathrm{~mm}$ in the west to $600 \mathrm{~mm}$ in the east of region (Gascuel-Odoux et al., 2010). The combination of an impervious bedrock and a wet climate leads to a high stream density (about $1 \mathrm{~km} / \mathrm{km}^{2}$ ), relatively shallow groundwater, and presence of hydromorphic riparian soils that cover about $20 \%$ of the land surface (Dupas et al., 2013). Brittany is a rural region, with only five cities $>50,000$ inhabitants and the largest city of Rennes hosting 210,000 inhabitants (2013 data). Land use is dominated by agriculture, and the Brittany agricultural sector contributed $12 \%$ of French agricultural production in 2010 ( $7 \%$ in 1950) on only $5 \%$ of France's surface area. A large part of the agricultural sector is devoted to intensive animal production, representing $20,55,41$, and $26 \%$ of national headcounts for dairy cows, pigs, egg chicken, and meat chicken, respectively. As a consequence of intensive agriculture, soil surface nitrogen surplus was $46 \mathrm{~kg} \mathrm{~N} / \mathrm{ha}$ in 2007 (Dupas et al., 2013) and median soil extractable phosphorus was $152 \mathrm{mg}$ P (Dyer)/kg in 2003 (Lemercier et al., 2008). This agricultural development has been relatively late but rapid after the second world war and the European Common Agricultural Policy (1962), which is only shortly before the start of river monitoring programs in seven rivers as early as the 1970 s.

\subsection{Monitoring Data and Catchment Characteristics}

This study focuses on the water quality parameters nitrate- $\mathrm{N}\left(\mathrm{N}-\mathrm{NO}_{3}{ }^{-}\right)$, soluble reactive phosphorus (SRP), and total phosphorus (TP) because these parameters are influenced by agricultural activities and they have been measured for up to five decades in the study area. We selected seven rivers for this data analysis based on the criteria that their water quality monitoring started in the 1970s for at least one of the parameters listed above and discharge data were available at the water quality monitoring station (Figure 1). Nitrate-N and SRP monitoring started in 1971 or 1976 while TP monitoring started in 1982 (Figure 2). The monitoring strategy was the same for all the catchments and throughout the study period, consisting in a regular sampling at fixed dates (monthly to bimonthly) during both base flow and stormflow periods. All discharge and water quality data were provided by water authorities (publicly available at http://osur.eau-loire-bretagne.fr/ and http://hydro.eaufrance.fr/).

Discharge data were available daily during the whole study period (1970-2016) while water quality monitoring had a monthly to bimonthly frequency and contained missing data before the 1990s (Figure 2). Despite discontinuities in the data set since the 1970s, the time series allows estimation of a baseline concentration for nitrate shortly after the start of rapid agricultural development in the 1960s.

The seven rivers selected have catchment areas ranging from 184.7 to $10,147.6 \mathrm{~km}^{2}$ at the monitoring station selected and include the three largest rivers of the region, namely, the Vilaine, Blavet, and Aulne (Table 1). In total, the catchments selected cover $53 \%$ of the Brittany region and are independent except for the Seiche, which is a subcatchment of the Vilaine. Agriculture represents 74 to $91 \%$ of the surface area, artificial surfaces $<7 \%$. Only the Vilaine catchment includes a large city $>50,000$ inhabitants, namely, the city of Rennes.

\subsection{Data Analysis}

Time series analysis was performed using the $\mathrm{R}$ software (R Development Core Team, 2008) and was threefold:

1. Long-term trends were extracted from monthly time series with the "Seasonal and Trend decomposition using Loess" method (R function STL; Cleveland et al., 1990). The STL method has been used in several previous water quality studies (Lloyd et al., 2014; Romero et al., 2016) to decompose time series into seasonal, long-term trend and irregular components by means of nonparametric regressions. The span of the Loess window for seasonal and long-term extractions was set to 12 and 72 months, respectively. The 72-month window was found to provide a good degree of smoothing for interpretation of interannual variations typically following 5- to 10-year cycles in the study area (Gascuel-Odoux et al., 2010). Because STL requires continuous and regularly spaced data (here monthly), missing data were interpolated using a seasonal Kalman filter (R package zoo; Zeileis \& Grothendieck, 2005), while data for months with more than one measurement were averaged. The "Breaks For Additive Season and Trend" method (R package BFAST; Verbesselt et al., 2010) was used to detect abrupt changes in water quality time series, in particular the bfast01 function to detect single breaks in the time series. We used a Mann-Kendall test to detect monotonic trends on both sides of the break (or on the whole time series when no break was detected), and the mean slopes were quantified using Sen's method (Sen, 1968). Finally, annual nitrate loads estimated by 

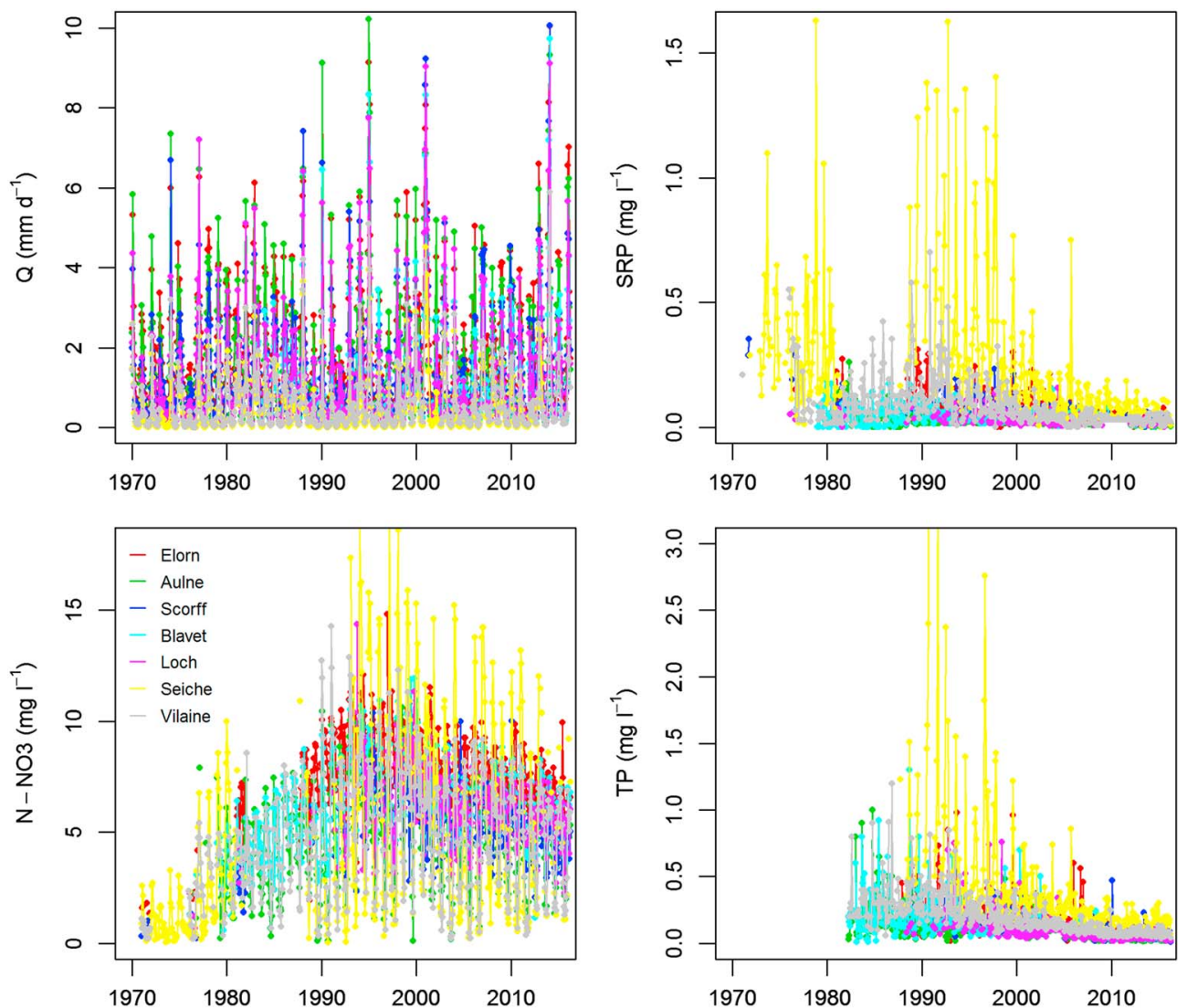

Figure 2. Monthly time series of discharge $(Q)$ nitrate-N, soluble reactive phosphorus (SRP), and total phosphorus (TP) in seven Brittany rivers.

the discharge weighted concentration method were plotted against long-term annual $\mathrm{N}$ surplus (Poisvert et al., 2017) to investigate time lags in the nitrogen input-output relationship from 1970 to 2016 . The $\mathrm{N}$ surplus was computed from a soil-surface mass balance including mineral fertilizers, manure, symbiotic fixation, and atmospheric deposition as inputs, and the biomass harvested or grazed as outputs (Poisvert et al., 2017), using agricultural statistical data available at the resolution of French counties (approximately $100 \mathrm{~km}^{2}$ ). Annual nitrate loads were computed with

Table 1

Catchment Properties

\begin{tabular}{|c|c|c|c|c|c|c|c|c|}
\hline & & Elorn & Aulne & Scorff & Blavet & Loch & Seiche & Vilaine \\
\hline & Size $\left(\mathrm{km}^{2}\right)$ & 260.7 & $1,472.0$ & 299.8 & $1,937.5$ & 183.7 & 804.7 & $10,147.6$ \\
\hline & Annual runoff (mm) & 683.0 & 569.3 & 531.5 & 452.6 & 445.6 & 182.5 & 233.9 \\
\hline \multirow[t]{4}{*}{ Topography } & Minimum elevation (m) & 9 & 9 & 19 & 15 & 20 & 18 & 4 \\
\hline & Maximum elevation (m) & 383 & 382 & 274 & 311 & 176 & 184 & 336 \\
\hline & Mean elevation (m) & 130 & 165 & 144 & 153 & 84 & 71 & 84 \\
\hline & Mean slope (\%) & 7.0 & 8.3 & 8.5 & 6.9 & 5.3 & 3.4 & 4.2 \\
\hline \multirow{3}{*}{ Parent material (\%) } & Granite (\%) & 34.2 & 10.4 & 79.1 & 36.2 & 67.5 & 2.5 & 8.4 \\
\hline & Micaschist (\%) & 2.6 & 0.0 & 20.9 & 11.1 & 0.0 & 0.0 & 3.6 \\
\hline & Schist (\%) & 61.1 & 84.4 & 0.0 & 49.1 & 30.2 & 90.8 & 70.9 \\
\hline \multirow[t]{6}{*}{ Land cover (\%) } & Artificial surfaces (\%) & 7.0 & 2.3 & 1.8 & 3.5 & 3.4 & 6.2 & 5.2 \\
\hline & Agricultural areas (\%) & 76.2 & 80.5 & 73.5 & 81.4 & 73.7 & 90.5 & 82.6 \\
\hline & Forest and seminatural areas (\%) & 16.4 & 16.6 & 24.7 & 14.8 & 22.8 & 3.1 & 11.7 \\
\hline & Water bodies (\%) & 0.5 & 0.7 & 0.0 & 0.3 & 0.1 & 0.2 & 0.4 \\
\hline & Potential wetlands (\%) & 23.7 & 22.8 & 16.6 & 20.9 & 22.6 & 24.0 & 25.1 \\
\hline & Population density (pop/ $/ \mathrm{km}^{2}$ ) & 86.8 & 49.5 & 53.5 & 54.3 & 72.7 & 117.3 & 114.7 \\
\hline
\end{tabular}




$$
\text { Load }=\mathrm{k} * \overline{\mathrm{Q}} * \frac{\sum_{\mathrm{i}} \mathrm{Ci} * \mathrm{Qi}}{\sum_{\mathrm{i}} \mathrm{Qi}}
$$

where $\mathrm{Ci}$ and Qi represent the nitrate concentration and discharge at the time of sampling, $\overline{\mathrm{Q}}$ is the mean annual discharge, and $\mathrm{k}$ is a conversion factor to obtain nitrate loads in $\mathrm{kg} \mathrm{N} \cdot \mathrm{ha}^{-1} \cdot$ year $^{-1}$. Input (surplus)-output (load) relationships were plotted for nitrate only due to availability of long-term $\mathrm{N}$ surplus data, which was not the case for P. Long-term annual load and surplus were smoothed using a Loess function, consistent with the STL method used for decomposition of monthly time series, to focus analysis on long-term trends and smooth the variations caused by interannual climate variability. The long-term load-surplus relationships were fitted with an empirical equation, previously developed for investigation of concentration-discharge hysteresis loops during storm events (Minaudo et al., 2017):

$$
\text { Load }=\mathrm{a} 1 * \text { surplus }+\mathrm{b} 1 * \mathrm{~d} \text { surplus } / \mathrm{dt}
$$

where $\mathrm{a} 1$ and $\mathrm{b} 1$ are the fitted parameters and b1 can be interpreted in terms of time lags, with lower negative b1 values indicating a slower (delayed) response of $\mathrm{N}$ load to $\mathrm{N}$ surplus variations.

2. Medium-term interannual variations linked to climate variability are less often investigated in the literature (Dupas et al., 2016; Mellander et al., 2018). Here we extracted these medium-term variations by difference between two STL trends with different degree of smoothing. The Loess window for long-term extraction was set to 180 months to obtain a very smoothed trend, which was subtracted from the long-term extraction with a 72-month window. The result of this subtraction extracts the medium-term interannual variations from the long-term multidecadal trend. Discharge was taken as an integrated hydroclimatic indicator that is influenced both by rainfall and evapotranspiration, itself correlated with temperature (Dupas, Mellander, et al., 2017). Interannual concentration-discharge relationships (smoothed and subtracted as explained above) were plotted and fitted with an empirical relationship:

$$
\text { Concentration }=\mathrm{a} 2 * \text { discharge }+\mathrm{b} 2 * \mathrm{~d} \text { discharge } / \mathrm{dt}
$$

The coefficient a2 takes a positive value in the case of an accretion pattern, that is, increasing concentrations during wetter years, and a negative value in the case of a dilution pattern, that is, decreasing concentrations during wetter years. The coefficient b2 takes a positive value in the case of a clockwise hysteresis loop, that is, higher concentration at the beginning of a succession of wet years, and a negative value in the case of a counterclockwise hysteresis loop, that is, higher concentration at the end of succession of wet years. The method was applied to three dry-wet cycles from 1990 to 1997 (period 1), from 1997 to 2004 (period 2), and from 2004 to 2010 (period 3).

3. Seasonal variations were investigated by computing the median of seasonal STL components with Loess windows such as in the long-term analysis, for each decade from 1970 to 2016. Seasonal variations were plotted in relative terms for comparison among parameters and among catchments (with the same $y$ axes), by dividing the median seasonal component by the long-term trend. Absolute seasonal variations, that is, not divided by the long-term trend, are shown in supporting information S1 (with y axes adapted to each parameter and catchment).

We chose to focus time series analysis on concentrations rather than loads (except for the $\mathrm{N}$ surplus-load relations) because previous studies have shown that (i) load dynamics are generally more influenced by discharge than concentrations (Musolff et al., 2017) and (ii) P load estimation is subjected to high uncertainties when calculated with data from infrequent sampling (Johnes, 2007).

\section{Results}

\subsection{Long-Term Trends}

Long-term discharge time series do not exhibit increasing or decreasing trends (Mann Kendall test, $p<0.05$ ) but are affected by large interannual variations controlled by climate variability. In particular, three dry-wet cycles are visible in Figure 3 from 1990 to 1997 (period 1), from 1997 to 2004 (period 2), and from 2004 to 2010 (period 3), and the effect of these dry-wet cycles is analyzed in section 3.2. Previous studies have 

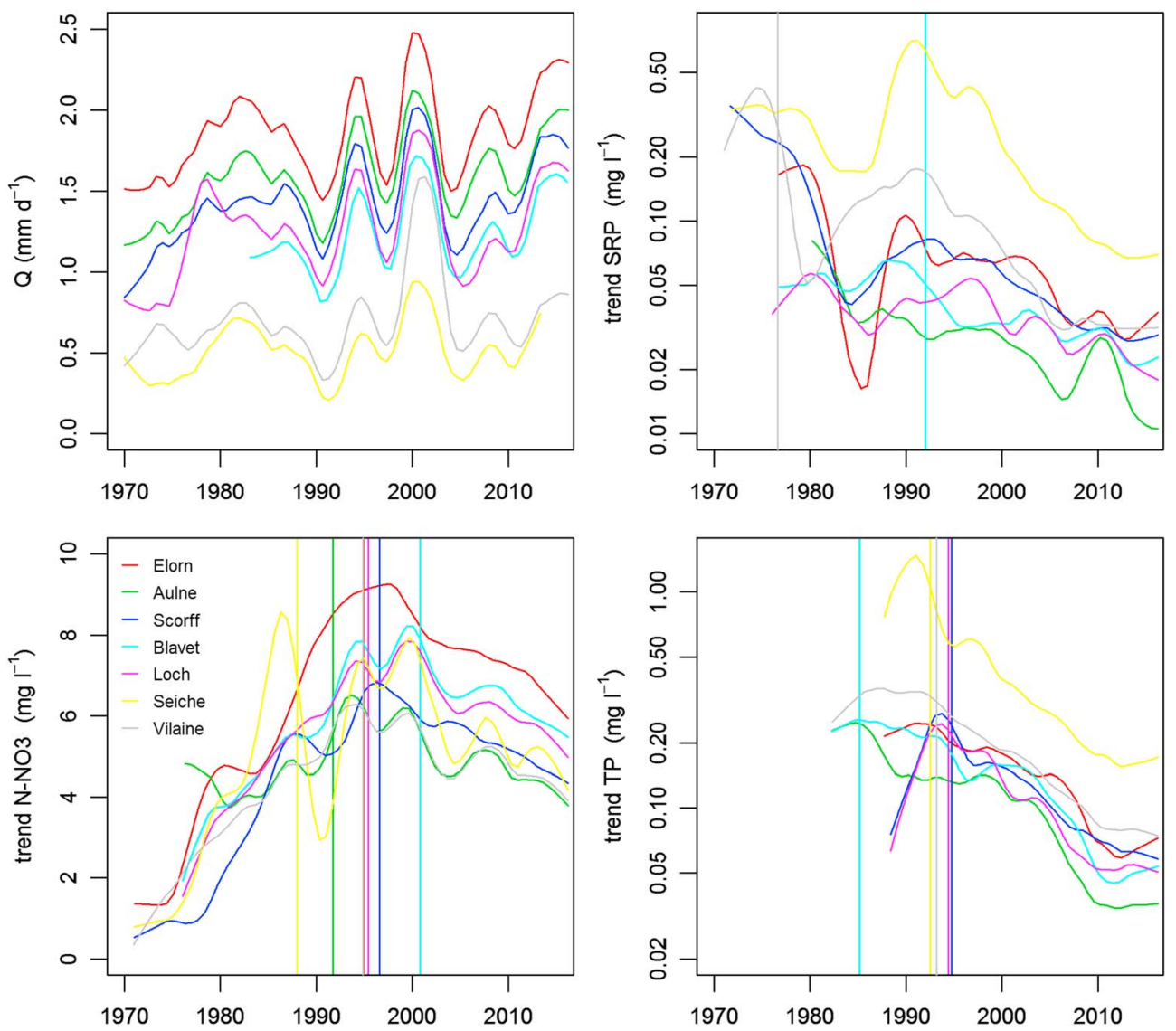

Figure 3. Long-term trend of discharge $(Q)$, nitrate- $\mathrm{N}$, soluble reactive phosphorus (SRP), and total phosphorus (TP) in seven Brittany rivers. Vertical bars indicate BFAST breakpoints. Note the log scale in the SRP and TP plots.

Table 2

Break Points in N-NO $\mathrm{N}_{3}$ SRP, and TP Time Series Identified by BFAST and Sen Slopes Before and After the Breakpoint

\begin{tabular}{llccc}
\hline & Station & Sen slope first period & Break point & Sen slope second period \\
\hline $\mathrm{N} \mathrm{NO}_{3}\left(\mathrm{mg} \mathrm{L}^{-1}\right)$ & Elorn & 0.36 & 1995 & -0.14 \\
& Aulne & 0.05 & 1992 & -0.10 \\
& Scorff & 0.28 & 1997 & -0.12 \\
& Blavet & 0.23 & 2001 & -0.12 \\
& Loc'h & 0.27 & 1995 & -0.11 \\
& Seiche & 0.49 & 1988 & -0.06 \\
& Vilaine & 0.24 & 1995 & -0.09 \\
$\mathrm{SRP}\left(\mu \mathrm{g} \mathrm{L}^{-1}\right)$ & Elorn & -2.26 & & \\
& Aulne & -0.92 & & \\
& Scorff & -2.76 & 1992 & -0.70 \\
& Blavet & 0.87 & & \\
& Loc'h & -0.69 & & -3.33 \\
& Seiche & -7.06 & 1977 & \\
$\mathrm{TP}\left(\mu \mathrm{g} \mathrm{L}^{-1}\right)$ & Vilaine & 36.33 & & -6.90 \\
& Elorn & -7.51 & 1995 & -7.49 \\
& Aulne & -6.06 & 1985 & -7.66 \\
& Scorff & 36.49 & 1994 & -23.53 \\
& Blavet & 11.79 & 1993 & -10.10 \\
\hline
\end{tabular}

Note. All trends are significant (Mann Kendall test, $p<0.05$ ). 


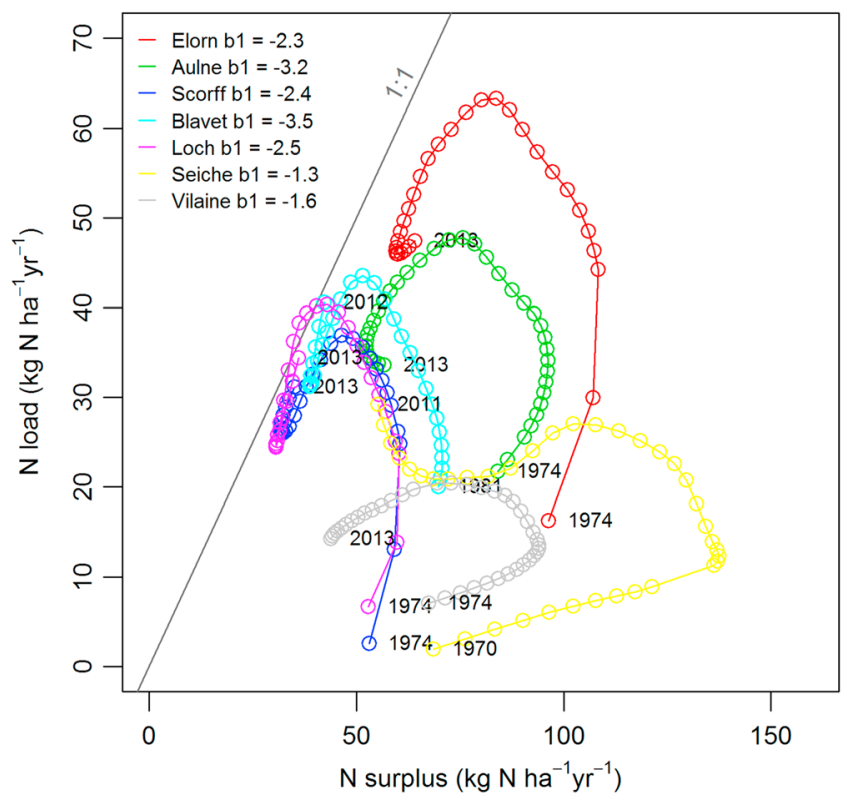

Figure 4. $\mathrm{N}$ surplus-N load plot in the seven studied rivers. Annual surplus and load estimation have been smoothed using a loess method to limit the effect of interannual climate variability. The b1 coefficient is obtained from fitting equation (2) to the data. shown that these dry-wet cycles were influenced by the North Atlantic Oscillation in western Europe (Gascuel-Odoux et al., 2010; Mellander et al., 2018). STL decomposition of concentration time series shows different long-term trends for nitrogen and phosphorus, while the two phosphorus forms SRP and TP exhibit similar trends during the period when both parameters have been measured simultaneously (1982-2016).

Nitrate- $\mathrm{N}$ trends show a gradual increase from 1971 to a maximum generally in the 1990s and a gradual decrease afterward. Nitrate-N concentrations in the four rivers with data before 1975 (Elorn, Scorff, Vilaine, and Seiche) exhibit initial concentrations below $1 \mathrm{mg} / \mathrm{L}$ and immediate increases from the beginning of the records. This indicates that baseline nitrate- $\mathrm{N}$ concentrations were likely well below $1 \mathrm{mg} / \mathrm{L}$ in the post Second World War period. Maximum nitrate-N concentrations in the $1990 \mathrm{~s}$ ranged from 6.2 to $8.8 \mathrm{mg} / \mathrm{L}$ and decreased to $3.5-6.2 \mathrm{mg} / \mathrm{L}$ in 2016 . The timing of maximum nitrate- $\mathrm{N}$ concentration ranged from 1988 (Seiche River) to 2001 (Blavet River), and was 1995 on average (Table 2 ). The increasing phase was generally faster than the decreasing phase, with seven significantly increasing Sen slopes (Mann Kendall test, $p<0.05$ ) ranging from 0.05 to $0.49 \mathrm{mg} \mathrm{N} \cdot \mathrm{L}^{-1} \cdot$ year $^{-1}$ and seven significant decreasing Sen slopes ranging from -0.14 to $-0.06 \mathrm{mg} \mathrm{N} \cdot \mathrm{L}^{-1} \cdot$ year $^{-1}$. Nitrogen surplus-load plots exhibit large counterclockwise hysteresis loops, with $\mathrm{N}$ surplus maxima during the 1985-1990 period and $\mathrm{N}$ load maxima during the 1995-2000 period, indicating a time lag of approximately 10 years between decrease in inputs (surplus) and decrease in outputs (loads) in the Brittany region (Figure 4). Most points in Figure 4 remain below the 1:1 line, showing an apparent $\mathrm{N}$ retention in all the catchments despite the nonstationarity highlighted by the hysteresis loop. The Seiche and Vilaine catchments in particular stood out from the other catchments, exhibiting highest apparent retention rates (i.e., highest distance below the 1:1 line) and quicker response to decreasing $\mathrm{N}$ surplus (i.e., as highlighted by the least negative b1 parameter).

SRP trends show two periods of high concentrations in the 1970s and late 1980s, and only the second one is visible in the TP trends due to later start of TP measurements in 1982. The absolute and relative magnitude of $\mathrm{P}$ concentrations during the two periods varied greatly among catchments, the Elorn, Scorff, Vilaine, and Seiche been particularly high in the $1970 \mathrm{~s}$ (>0.25 mg SRP/L) and the Seiche remained the highest during the 1980-1990s (>0.6 mg SRP/L and approximately $1.4 \mathrm{mg}$ TP/L). Since the early 1990s, SRP and TP have decreased significantly in all rivers (Mann Kendall test, $p<0.05$ ) at rates ranging from -7 to $-1 \mu \mathrm{g} \mathrm{SRP} \cdot \mathrm{L}^{-1} \cdot$ year $^{-1}$ and from -24 to $-6 \mu \mathrm{g} \mathrm{TP} \cdot \mathrm{L}^{-1} \cdot$ year $^{-1}$.

\subsection{Medium-Term Interannual Variations}

Medium-term variations during dry-wet interannual cycles show consistent patterns among the three different periods studied for a given parameter, and contrasting responses among parameters. Hence, the three dry-wet cycles are presented together ( 3 periods $\times 7$ catchments $=21$ catchment periods). Figure 5 shows concentration-discharge relationships during the three periods studied, and Table 3 counts the number of accretion (increasing concentration during wet years) and dilution (decreasing concentration during wet years) patterns, and clockwise and counterclockwise hysteresis loops during a dry-wet cycle. Accretion/dilution patterns and hysteresis loop direction are identified from the sign of the a2 and b2 parameters in equation (3).

For nitrate-N, a majority of accretion patterns (16/21 catchment periods) and clockwise loops (16/21 catchment periods) was observed. Only the Scorff and Elorn rivers exhibited dilution patterns for nitrate-N. For SRP, a majority of dilution patterns (15/21 catchment periods) was observed and the number of clockwise and counterclockwise loops was similar (8/21 and 12/21, respectively). For TP, the same number of dilution and accretion patterns was observed (10/21 and 10/21, respectively) and clockwise hysteresis loops were dominant (14/21 catchment periods). 

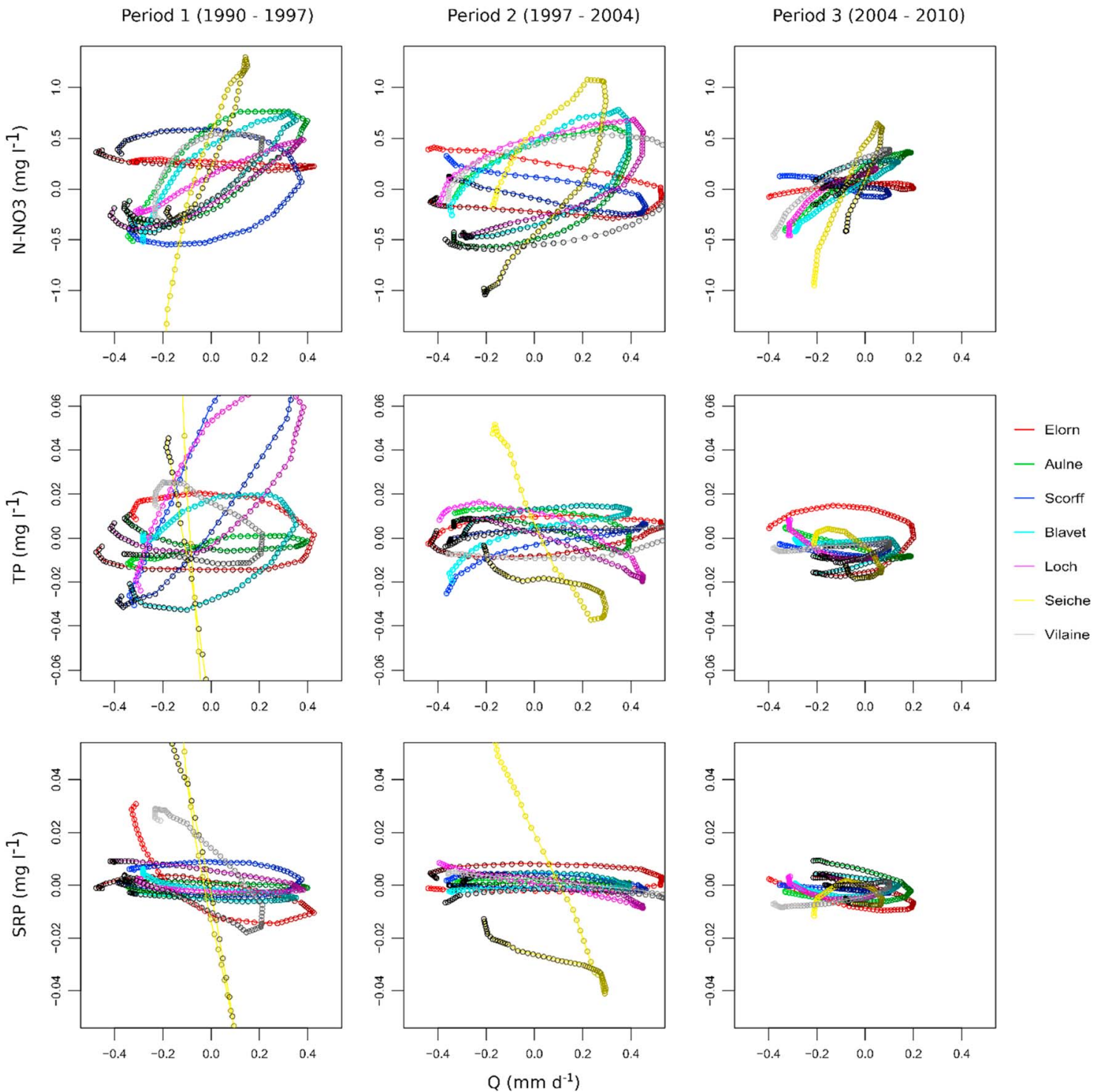

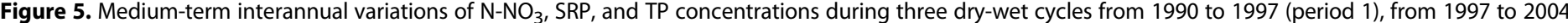
(period 2), and from 2004 to 2010 (period 3). The directions of the hysteresis loops are indicated by the color gradation from color used for each river in the legend at the beginning of each period to black at the end.

Table 3

Slopes and Hysteresis Directions During Three Interannual Dry-Wet Cycles for Four Water Quality Parameters and Seven Rivers in Brittany

\begin{tabular}{|c|c|c|c|c|c|c|}
\hline & \multicolumn{2}{|r|}{$\mathrm{N}-\mathrm{NO}_{3}$} & \multicolumn{2}{|r|}{ SRP } & \multicolumn{2}{|r|}{ TP } \\
\hline & $\begin{array}{l}\text { Slope (positive/ } \\
\text { negative/ } \\
\text { nonsignificant) }\end{array}$ & $\begin{array}{l}\text { Hysteresis loop (clockwise/ } \\
\text { counterclockwise/ } \\
\text { nonsignificant) }\end{array}$ & $\begin{array}{l}\text { Slope (positive/ } \\
\text { negative/ } \\
\text { nonsignificant) }\end{array}$ & $\begin{array}{l}\text { Hysteresis loop (clockwise/ } \\
\text { counterclockwise/ } \\
\text { nonsignificant) }\end{array}$ & $\begin{array}{l}\text { Slope (positive/ } \\
\text { negative/ } \\
\text { nonsignificant) }\end{array}$ & $\begin{array}{c}\text { Hysteresis loop (clockwise/ } \\
\text { counterclockwise/ } \\
\text { nonsignificant) }\end{array}$ \\
\hline Period 1 & $6 / 1 / 0$ & $6 / 1 / 0$ & $0 / 6 / 1$ & $3 / 3 / 1$ & $3 / 3 / 1$ & $5 / 0 / 2$ \\
\hline Period 2 & $5 / 2 / 0$ & $7 / 0 / 0$ & $1 / 4 / 2$ & $4 / 3 / 0$ & $4 / 3 / 0$ & $4 / 3 / 0$ \\
\hline Period 3 & $5 / 1 / 1$ & $3 / 2 / 2$ & $2 / 5 / 0$ & $1 / 6 / 0$ & $3 / 4 / 0$ & $5 / 1 / 1$ \\
\hline $\begin{array}{l}\text { Total } \\
\text { three } \\
\text { periods }\end{array}$ & $16 / 4 / 1$ & $16 / 3 / 2$ & $3 / 15 / 3$ & $8 / 12 / 1$ & $10 / 10 / 1$ & $14 / 4 / 3$ \\
\hline
\end{tabular}




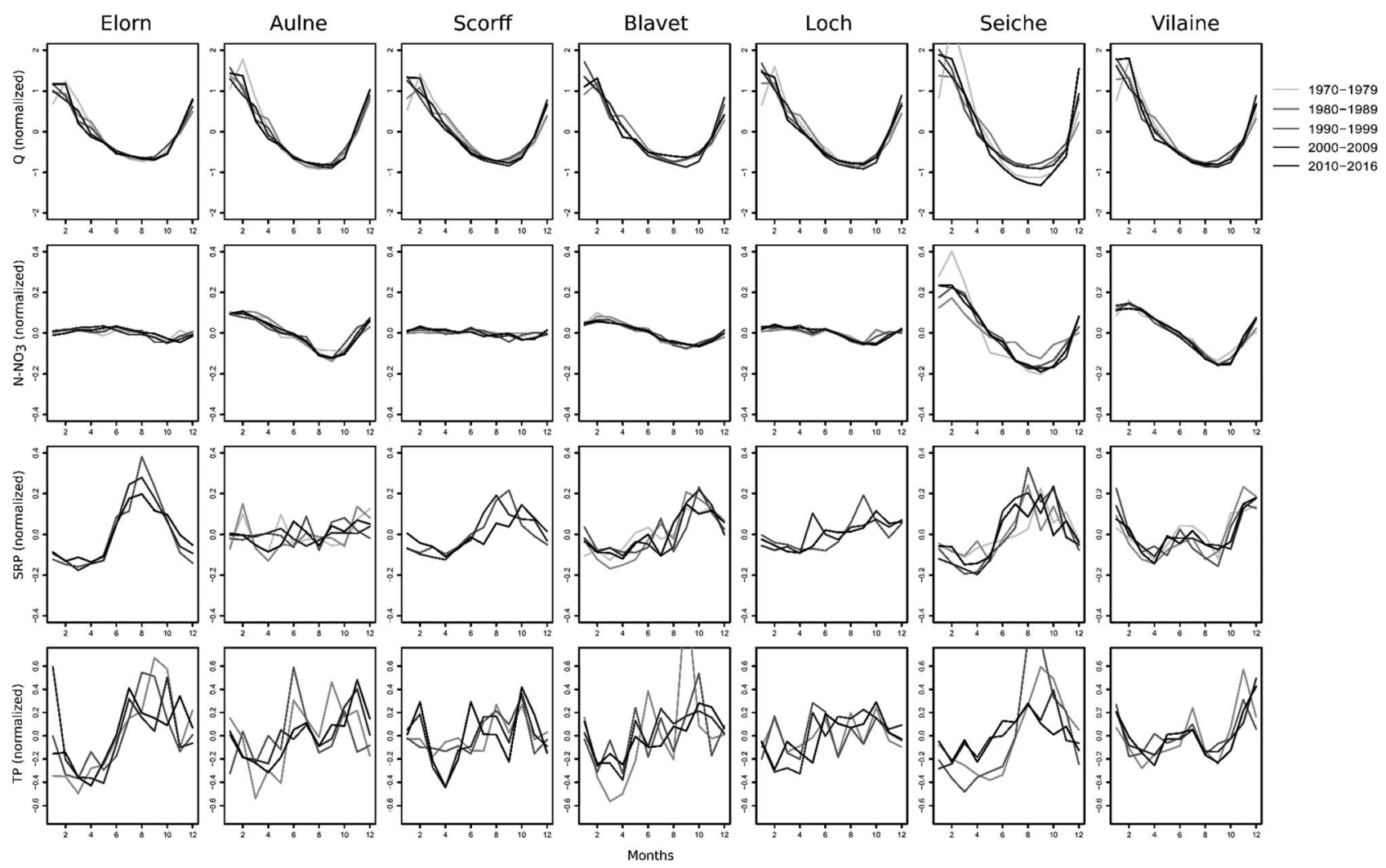

Figure 6. Relative seasonal variations in discharge and concentrations.

\subsection{Intraannual Seasonal Variations}

Seasonal variations of discharge and concentrations remained in the same phase and with similar relative amplitude throughout the study period, as shown by the overlapping lines for each parameter and each catchment in Figure 6. This means that concentration seasonal amplitudes were (approximately proportionally) highest during decades of high concentrations, compared to decades with lower concentrations. Among catchments and for each parameter, seasonal variations were in phase (i.e., seasonal maxima and minima occurred during the same months) but seasonal amplitudes differed. The Seiche and Vilaine catchments stood out from the other catchments, with relatively low annual runoff $<250 \mathrm{~mm} /$ year (versus $>400 \mathrm{~mm} /$ year for the other five catchments; Table 1) and a higher discharge relative seasonality (Figure 6). Nitrate seasonal maxima occurred during the winter period from December to March and seasonal minima during the late summer from August to October; that is, it was synchronous with discharge in all the rivers. The Seiche and Vilaine rivers exhibited the largest seasonal nitrate-N amplitudes, whereas the Elorn, Scorff, and Loc'h rivers exhibited the lowest seasonal nitrate-N amplitudes. SRP and TP seasonal maxima generally occurred during the late summer period to early fall from July to October, opposite to discharge, sometimes with a secondary winter peak, in phase with discharge (e.g., SRP and TP in the Vilaine river). SRP and TP seasonal minima generally occurred during the spring season in April. The Seiche, Vilaine, and Elorn rivers exhibited the largest seasonal amplitudes for SRP, whereas the Aulne and Loc'h rivers hardly exhibited a periodic signal. The TP seasonal signal was more "noisy" than the SRP signal, with nonperiodic intraannual variations.

\section{Discussion}

All seven rivers generally exhibited synchronous concentration dynamics (Abbott et al., 2017) at the three time scales studied: multidecadal, interannual, and seasonal. It is therefore possible to infer the trajectory of a typical catchment of western France from the 1970s to 2016, from the interpretation of concentration dynamics analyzed in combination with potential controlling factors (section 4.1). Exceptions to the typical synchronous patterns observed and differences in the amplitudes of synchronous variations among catchment can be interpreted in terms of local properties of land use and management, climate, and/or lithology (section 4.2). 


\subsection{Synchronous Concentration Dynamics Across Time Scales}

Changes in climate and weather are not likely to explain past long-term (multidecadal) concentration trends as data showed no long-term trend in discharge, and discharge is a result of rainfall and evapotranspiration, itself correlated with temperature (Gascuel-Odoux et al., 2010). Similarly, the Brittany region has long been an agricultural region and no substantial change in the percentage of agriculture land use has occurred during the study period. Hence, long-term trends in concentrations and fluxes can be interpreted for the most part in terms of changes in point source inputs and land management (i.e., farming system types and agricultural practices) with the European Nitrate Directive and Urban Waste Water Directive as possible drivers of these changes. Weather variations are more likely to explain a large part of medium-term variations during interannual dry-wet cycles and seasonal variations.

The long-term $\mathrm{N}$ and $\mathrm{P}$ concentration trends seem to be unrelated to each other in the seven catchments studied. Typically, nitrate- $\mathrm{N}$ rose sharply from the beginning of the record until approximately 1995 ( mean $=+0.27 \mathrm{mg} \mathrm{N} \cdot \mathrm{L}^{-1} \cdot$ year $^{-1}$ ) and decreased more gradually (mean $=-0.10 \mathrm{mg} \mathrm{N} \cdot \mathrm{L}^{-1} \cdot$ year $^{-1}$ ) afterward. On the other hand, SRP decreased continuously from the beginning of the record or after an earlier breakpoint in 1977 or 1992 (mean $=-3 \mu \mathrm{g} \mathrm{SRP} \cdot \mathrm{L}^{-1} \cdot$ year ${ }^{-1}$ ). TP monitoring started only in 1982, which reduces confidence in the breakpoints detected in the early years of the records, but TP trends appeared to follow those of SRP.

\subsubsection{Nitrate Dynamics}

The long-term trend in nitrate- $\mathrm{N}$ concentration (or load, as discharge did not exhibit long-term trends) followed that of the $\mathrm{N}$ surplus with a time lag of around 10 years between input (surplus) and output (load) variations, leading to counterclockwise hysteresis loops in these shallow groundwater-dominated catchments. Similar counterclockwise hystereses have been found in several catchments worldwide (Howden, Burt, Worrall, et al., 2011; Howden, Burt, Mathias, et al., 2011; Kelly et al., 2015; Kopacek et al., 2013; Stets et al., 2015; Van Meter et al., 2017; Van Meter \& Basu, 2017; Viaroli et al., 2018). It must be noted that the 10-year response time in Brittany catchments is a function not only of the catchment properties but also of the monitoring strategy deployed, as previous studies have shown that higher-frequency sampling can detect shorter response times because they better capture "hot moments" of transport when fast responding flow paths are activated (Melland et al., 2018; Wall et al., 2012). N load remained below N surplus for all catchments and all dates (Figure 4), indicating a negative mass balance at the catchment scale. Similar negative balances have been found in several previous catchment studies, and some authors have questioned whether this was due to permanent retention processes within the catchment or to nonsteady state conditions related to the transit of $\mathrm{N}$ through the catchment (Dupas et al., 2015; Howden et al., 2010). Here long-term data covering increasing and decreasing phase for both $\mathrm{N}$ inputs (surplus) and outputs (load) show that, although the catchments were never in steady state conditions as shown by the large hysteresis loops in Figure 4, they also have always been a net sink for nitrate-N. Hence, the occurrence of permanent retention processes such as denitrification is confirmed by the data. The nonsteady state conditions question the relevance of the calibration procedure in most modeling studies, where parameters are calibrated by linking input data and observed nitrate concentration or load, with an implicit steady state assumption which our data show is not verified in the context of the shallow groundwater-dominated catchments of Brittany.

The influence of medium-term interannual dry-wet cycles on nitrate dynamics have rarely been studied and most existing studies have focused on nitrate loads rather than concentrations (e.g., Gascuel-Odoux et al., 2010; Outram et al., 2016), although load variations are more likely to follow those of discharge than concentration (Basu et al., 2010; Musolff et al., 2017). Here we focused analysis on nitrate concentration and the typical pattern observed during a wet period is an accretion pattern with a clockwise hysteresis. The dominant accretion pattern indicates increased nitrate mobilization during wet periods, which is coherent with a dominant diffuse origin of nitrate (Abbott et al., 2018; Dupas et al., 2016; Musolff et al., 2016). Previous catchment studies in the Brittany region, including in situ monitoring of groundwater at several depths and distances along hillslopes, have identified the presence a large pool of legacy $\mathrm{N}$ in the shallow groundwater in the upslope domain of two representative headwater catchments (Aubert et al., 2013; Molenat et al., 2008). Wet periods increase the intensity and duration of connectivity between this nitrate source and the river network. The clockwise hysteresis shows a degree of source limitation in the concentration discharge relationship, indicating nonsteady state conditions at the scale of approximately five-year dry-wet cycles: $\mathrm{N}$ accumulates during dry periods and wet periods export part of the previously accumulated $\mathrm{N}$. 
The seasonal nitrate dynamics, with a dominant pattern of increasing concentration during the wet winter, is also coherent with the latter hydrological interpretation suggesting higher export of $\mathrm{N}$ sources when catchments connectivity is maximal (Burt et al., 1988; Dupas, Musolff, et al., 2017; Musolff et al., 2016; Outram et al., 2016). However, this purely hydrological explanation of the seasonality can be amplified by denitrification processes that occur in conditions with warm temperature and low residence time, that is, during the summer season, in the wetland area and the river network (Rode et al., 2016).

\subsubsection{Phosphorus Dynamics}

Phosphorus long-term trends are interpreted jointly for SRP and TP as data show that TP long-term dynamics followed those of SRP during the period when both parameters have been measured. SRP concentrations peaked on average in 1983, that is, before the $\mathrm{N}$ surplus peak, and therefore, SRP long-term concentration trends cannot be driven predominantly by agricultural inputs (assuming that the soil surface $\mathrm{N}$ surplus is a good indicator of both $\mathrm{N}$ and $\mathrm{P}$ diffuse inputs). The dominant point source influence on long $\mathrm{P}$ trend is confirmed by expert knowledge on the upgrading of wastewater treatment plants and reduction of polyphosphates in detergents since the 1970s (Viaroli et al., 2018). The apparent drop in SRP from 1980 to 1990 is visible in catchments with missing data during this decade (Figure 2), and this pattern is likely an artifact caused by our interpolation algorithm. However, the long-term $P$ trends appear to level off after 2010 in most rivers (Figure 3), suggesting that further decrease in $\mathrm{P}$ concentrations will require tackling diffuse $\mathrm{P}$ sources.

Medium-term interannual dry-wet cycles have contrasting influences for SRP and TP. The dominant SRP response to a succession of wet years is a dilution pattern with variable (or no) hysteresis types, consistent with the hypothesis of point source dilution (Bowes et al., 2014; Jarvie et al., 2006; Neal et al., 2010; Withers et al., 2014). Contrary to SRP, TP response to a succession of wet years exhibited nearly equal proportions of dilution and accretion patterns, arguably as a result of opposite mobilization and dilution effects. TP hysteresis loops were dominantly clockwise, indicating a source limitation: one possible interpretation is that SRP is retained in the river network (sediment or biomass) during dry years and remobilized in the form of particulate $P$ or unreactive dissolved $P$ (thus accounted in TP) during wetter years (Jarvie et al., 2012).

The dominant $P$ seasonal concentration pattern, with a majority of high SRP and TP concentrations during the summer low flow season, is also consistent with the hypothesis of the degree of dilution of point sources being the main driver of P seasonal cycles (Bowes et al., 2015). However, SRP seasonal patterns do not simply mirror discharge as would be expected if the degree of dilution of point source was the only controlling factor: SRP and TP seasonal minima generally occurred during the spring season, that is, not during the period of highest discharge. A possible interpretation is the influence of in-stream biological uptake (Minaudo et al., 2015) and this hypothesis is consistent with the largest spring SRP minimum observed in the Vilaine river, that is, in the largest river. The fact that $\mathrm{P}$ concentration dynamics appeared to be controlled predominantly by the degree of dilution of point sources does not necessarily mean that point sources represent the majority of annual P loads, especially for the most recent years. Indeed, the high concentrations attributed to points sources occur during the summer low-flow period when discharge (and consequently load) is at its lowest, while the winter discharge can transport larger amounts from diffuse source despite winter P concentrations being lower. For example, a recent load apportionment study showed that diffuse $\mathrm{P}$ emissions represented $70 \%$ of annual loads in the Brittany region during the 2007-2011 period despite concentrations being still at their highest during the summer low-flow period (Legeay \& Gruau, 2014).

\subsection{Variability Among Catchments: Controlling Factors}

Despite the catchments selected exhibiting similar dynamics for each water quality parameter, termed synchrony by Abbott et al. (2017), differences in the exact timings and amplitudes of variations can be interpreted according to the catchments' physical properties.

The nested Seiche and Vilaine catchments, both with a dominance of schist and with the lowest annual runoff (Table 1), exhibited the largest seasonal discharge amplitudes (Figure 6). They also exhibited the largest $\mathrm{N}$ and $\mathrm{P}$ seasonal amplitudes (Figure 6 and supporting information S1), suggesting a dominant runoff control on nutrient seasonality (Abbott et al., 2018).

\subsubsection{Nitrate Dynamics}

The large nitrate seasonal amplitudes in the Seiche and Vilaine rivers can be explained either by high variability in hydrological transport or by high summer retention linked to longer residence times in retention hot spots of the catchments (Pinay et al., 2015). Figure 4 reveals a higher apparent retention in these two catchments, 
suggesting that denitrification takes place in their soils or river networks. By extension, we hypothesize that denitrification is also the cause of the largest seasonal amplitudes in the Seiche and Vilaine rivers. The fact that nitrate seasonal amplitudes do not increase when moving downstream from the Seiche to the Vilaine outlet could be interpreted as retention taking place predominantly in soils rather than in-stream, as shown by Dupas, Musolff, et al. (2017) in central Germany. However, the Seiche catchment exceeds $800 \mathrm{~km}^{2}$ and instream retention can be observed in catchments of this size (Mulholland et al., 2008; Rode et al., 2016); thus, the respective control of terrestrial versus in-stream retention is difficult to disentangle. The Seiche and Vilaine rivers had the shortest response time to a decrease in the $\mathrm{N}$ surplus, as highlighted by their higher b1 coefficient (equation (2)). This could be due to higher denitrification in these catchments leading to lower legacy N storage (Van Meter et al., 2017), which is consistent with their flatter topography and higher percentage of riparian wetlands. The Elorn, Scorff, and Loc'h rivers hardly exhibited seasonal nitrate cycles, and these three catchments are at the same time the smallest and with presence of granite. It is therefore difficult, by looking at these three catchments alone, to conclude whether summer nitrate retention takes place predominantly in soils (which could explain the difference between granite and schist catchments) or in-stream (which could explain the smaller seasonal amplitudes in the smaller catchments). Two of these catchments, namely, the Elorn and Scorff, exhibited nitrate dilution patterns during wet years (Figure 5), which is consistent with their lack of positive nitrate-discharge seasonal relationships observed in the other catchments.

\subsubsection{Phosphorus Dynamics}

The high seasonal amplitude for SRP in the Seiche and Vilaine rivers can be explained by their large seasonal discharge variability and high percentage of artificial surfaces, indicative of point sources. The Elorn catchment, that is, the third catchment with large SRP seasonal amplitudes, was the wettest and with the lowest seasonal discharge amplitude, but had the highest percentage of artificial surfaces. Hence, SRP seasonal variations are predominantly determined by the amount of point sources and their degree of dilution (Bowes et al., 2008). The Aulne, Scorff, and Vilaine rivers exhibited the largest winter TP peaks, which can be explained either by remobilization of $P$ stored in river sediments, or diffuse emission from soils. The large size of the Aulne and Vilaine catchments support the hypothesis of sediment remobilization predominantly controlling winter TP peaks, whereas the steeper slopes and lower percentage of riparian wetlands in the Scorff catchment support the hypothesis of diffuse emissions being the dominant control. Hence, it is difficult to precisely disentangle both effects in the other catchments (Jarvie et al., 2012).

\section{Conclusions}

The $\mathrm{N}$ and $\mathrm{P}$ export trajectories of seven rivers dominated by shallow groundwater in western France were investigated from multidecadal to seasonal time scales, through analysis of long-term, low-frequency monitoring data. Results show that multidecadal $\mathrm{N}$ and $\mathrm{P}$ trends were mainly driven by $\mathrm{N}$ and $\mathrm{P}$ diffuse and point source inputs, respectively, with response times for nitrate being controlled by the amount of legacy $\mathrm{N}$ stored in the catchment. At medium-term interannual time scales, climate variability was the dominant control on concentration dynamics, which implies that evaluation of water quality mitigation programs should cover at least five years to decipher their effect from the effect of climate variations. Seasonally, N and P dynamics were typical of diffuse and point source dominated exports, respectively, similar to many catchments of the temperate zone. In-stream retention and remobilization processes, however, lead to difficulties in extracting the P land-to-river export signal from in-stream processes in these mesoscale catchments. Dominant controls on differences among catchments can often be inferred from catchment properties, but ambiguity issues (i.e., when the same observation can have several possible origins/interpretations) arose. Future work will thus focus on the spatial variability of even smaller, and possibly nested, catchments to test the conclusions presented in the present long-term study.

Acknowledgments

The authors would like to thank Cécile Poisvert and Florence Curie for providing the long-term $\mathrm{N}$ surplus data. Water quality and discharge data used in this study are available from public repositories at http://osur.eau-loirebretagne.fr/ and http://hydro.eaufrance.fr/.

\section{References}

Abbott, B. W., Gruau, G., Zarnetske, J. P., Moatar, F., Barbe, L., Thomas, Z., et al. (2017). Unexpected spatial stability of water chemistry in headwater stream networks. Ecology Letters, 21(2), 296-308. https://doi.org/10.1111/ele.12897

Abbott, B. W., Moatar, F., Gauthier, O., Fovet, O., Antoine, V., \& Ragueneau, O. (2018). Trends and seasonality of river nutrients in agricultural catchments: 18 years of weekly citizen science in France. Science of the Total Environment, 624, 845-858. https://doi.org/10.1016/ j.scitotenv.2017.12.176

Aubert, A. H., Gascuel-Odoux, C., Gruau, G., Akkal, N., Faucheux, M., Fauvel, Y., et al. (2013). Solute transport dynamics in small, shallow groundwater-dominated agricultural catchments: Insights from a high-frequency, multisolute $10 \mathrm{yr}$-long monitoring study. Hydrology and Earth System Sciences, 17(4), 1379-1391. https://doi.org/10.5194/hess-17-1379-2013 
Basu, N. B., Destouni, G., Jawitz, J. W., Thompson, S. E., Loukinova, N. V., Darracq, A., et al. (2010). Nutrient loads exported from managed catchments reveal emergent biogeochemical stationarity. Geophysical Research Letters, 37, L23404. https://doi.org/10.1029/ 2010GL045168

Billen, G., Garnier, J., Nemery, J., Sebilo, M., Sferratore, A., Barles, S., et al. (2007). A long-term view of nutrient transfers through the seine river continuum. Science of the Total Environment, 375(1-3), 80-97. https://doi.org/10.1016/j.scitotenv.2006.12.005

Bishop, K., Buffam, I., Erlandsson, M., Folster, J., Laudon, H., Seibert, J., \& Temnerud, J. (2008). Aqua incognita: The unknown headwaters. Hydrological Processes, 22(8), 1239-1242. https://doi.org/10.1002/hyp.7049

Bowes, M. J., Jarvie, H. P., Halliday, S. J., Skeffington, R. A., Wade, A. J., Loewenthal, M., et al. (2015). Characterising phosphorus and nitrate inputs to a rural river using high-frequency concentration-flow relationships. The Science of the Total Environment, 511, 608-620. https:// doi.org/10.1016/j.scitotenv.2014.12.086

Bowes, M. J., Jarvie, H. P., Naden, P. S., Old, G. H., Scarlett, P. M., Roberts, C., et al. (2014). Identifying priorities for nutrient mitigation using river concentration-flow relationships: The Thames basin, UK. Journal of Hydrology, 517, 1-12. https://doi.org/10.1016/j.jhydrol.2014.03.063

Bowes, M. J., Smith, J. T., Jarvie, H. P., \& Neal, C. (2008). Modelling of phosphorus inputs to rivers from diffuse and point sources. Science of the Total Environment, 395(2-3), 125-138. https://doi.org/10.1016/j.scitotenv.2008.01.054

Burt, T. P., Arkell, B. P., Trudgill, S. T., \& Walling, D. E. (1988). Stream nitrate levels in a small catchment in south West England over a period of 15 years (1970-1985). Hydrological Processes, 2(3), 267-284. https://doi.org/10.1002/hyp.3360020307

Burt, T. P., Howden, N. J. K., Worrall, F., \& McDonnell, J. J. (2011). On the value of long-term, low-frequency water quality sampling: Avoiding throwing the baby out with the bathwater. Hydrological Processes, 25(5), 828-830. https://doi.org/10.1002/hyp.7961

Cleveland, R. B., Cleveland, W. S., McRae, J. E., \& Terpenning, I. (1990). STL: A seasonal-trend decomposition procedure based on loess. Journal of Official Statistics, 6(3), 3-73.

Dupas, R., Curie, F., Gascuel-Odoux, C., Moatar, F., Delmas, M., Parnaudeau, V., \& Durand, P. (2013). Assessing N emissions in surface water at the national level: Comparison of country-wide vs. regionalized models. Science of the Total Environment, 443, 152-162. https://doi.org/ 10.1016/j.scitotenv.2012.10.011

Dupas, R., Delmas, M., Dorioz, J. M., Garnier, J., Moatar, F., \& Gascuel-Odoux, C. (2015). Assessing the impact of agricultural pressures on N and P loads and eutrophication risk. Ecological Indicators, 48, 396-407. https://doi.org/10.1016/j.ecolind.2014.08.007

Dupas, R., Jomaa, S., Musolff, A., Borchardt, D., \& Rode, M. (2016). Disentangling the influence of hydroclimatic patterns and agricultural management on river nitrate dynamics from sub-hourly to decadal time scales. Science of the Total Environment, 571, 791-800. https://doi. org/10.1016/j.scitotenv.2016.07.053

Dupas, R., Mellander, P. E., Gascuel-Odoux, C., Fovet, O., McAleer, E. B., McDonald, N., et al. (2017). The role of mobilisation and delivery processes on contrasting dissolved nitrogen and phosphorus exports in groundwater fed catchments. Science of the Total Environment, 599-600, 1275-1287.

Dupas, R., Musolff, A., Jawitz, J. W., Rao, P. S. C., Jaeger, C. G., Fleckenstein, J. H., et al. (2017). Carbon and nutrient export regimes from headwater catchments to downstream reaches. Biogeosciences, 14, 4391-4407. https://doi.org/10.5194/bg-14-4391-2017

Fovet, O., Ruiz, L., Faucheux, M., Molenat, J., Sekhar, M., Vertes, F., et al. (2015). Using long time series of agricultural-derived nitrates for estimating catchment transit times. Journal of Hydrology, 522, 603-617. https://doi.org/10.1016/j.jhydrol.2015.01.030

Galloway, J. N., Dentener, F. J., Capone, D. G., Boyer, E. W., Howarth, R. W., Seitzinger, S. P., et al. (2004). Nitrogen cycles: Past, present, and future. Biogeochemistry, 70(2), 153-226. https://doi.org/10.1007/s10533-004-0370-0

Gascuel-Odoux, C., Aurousseau, P., Durand, P., Ruiz, L., \& Molenat, J. (2010). The role of climate on inter-annual variation in stream nitrate fluxes and concentrations. Science of the Total Environment, 408(23), 5657-5666. https://doi.org/10.1016/j.scitotenv.2009.05.003

Hartmann, J., Jansen, N., Kempe, S., \& Dürr, H. H. (2007). Geochemistry of the river Rhine and the upper Danube: Recent trends and lithological influence on baselines. Journal of Environmental Science for Sustainable Society, 1, 39-46. https://doi.org/10.3107/jesss.1.39

Howden, N. J. K., Burt, T. P., Mathias, S. A., Worrall, F., \& Whelan, M. J. (2011). Modelling long-term diffuse nitrate pollution at the catchmentscale: Data, parameter and epistemic uncertainty. Journal of Hydrology, 403(3-4), 337-351. https://doi.org/10.1016/j.jhydrol.2011.04.012

Howden, N. J. K., Burt, T. P., Worrall, F., Mathias, S., \& Whelan, M. J. (2011). Nitrate pollution in intensively farmed regions: What are the prospects for sustaining high-quality groundwater? Water Resources Research, 47, W00L02. https://doi.org/10.1029/2011WR010843

Howden, N. J. K., Burt, T. P., Worrall, F., Whelan, M. J., \& Bieroza, M. (2010). Nitrate concentrations and fluxes in the river Thames over 140 years (1868-2008): Are increases irreversible? Hydrological Processes, 24(18), 2657-2662. https://doi.org/10.1002/hyp.7835

Hrachowitz, M., Benettin, P., van Breukelen, B. M., Fovet, O., Howden, N. J., Ruiz, L., et al. (2016). Transit times-The link between hydrology and water quality at the catchment scale. Wiley Interdisciplinary Reviews Water, 3(5), 629-657.

Jarvie, H. P., Neal, C., \& Withers, P. J. A. (2006). Sewage-effluent phosphorus: A greater risk to river eutrophication than agricultural phosphorus? Science of the Total Environment, 360(1-3), 246-253. https://doi.org/10.1016/j.scitotenv.2005.08.038

Jarvie, H. P., Sharpley, A. N., Scott, J. T., Haggard, B. E., Bowes, M. J., \& Massey, L. B. (2012). Within-river phosphorus retention: Accounting for a missing piece in the watershed phosphorus puzzle. Environmental Science \& Technology, 46(24), 13,284-13,292. https://doi.org/10.1021/ es303562y

Jarvie, H. P., Withers, P. J. A., Bowes, M. J., Palmer-Felgate, E. J., Harper, D. M., Wasiak, K., et al. (2010). Streamwater phosphorus and nitrogen across a gradient in rural-agricultural land use intensity. Agriculture Ecosystems \& Environment, 135(4), 238-252. https://doi.org/10.1016/ j.agee.2009.10.002

Johnes, P. J. (2007). Uncertainties in annual riverine phosphorus load estimation: Impact of load estimation methodology, sampling frequency, baseflow index and catchment population density. Journal of Hydrology, 332(1-2), 241-258. https://doi.org/10.1016/ j.jhydrol.2006.07.006

Kelly, V., Stets, E. G., \& Crawford, C. (2015). Long-term changes in nitrate conditions over the 20th century in two Midwestern Corn Belt streams. Journal of Hydrology, 525, 559-571. https://doi.org/10.1016/j.jhydrol.2015.03.062

Kopacek, J., Hejzlar, J., Porcal, P., \& Posch, M. (2017). Trends in riverine element fluxes: A chronicle of regional socio-economic changes. Water Research, 125, 374-383. https://doi.org/10.1016/j.watres.2017.08.067

Kopacek, J., Hejzlar, J., \& Posch, M. (2013). Factors controlling the export of nitrogen from agricultural land in a large central European catchment during 1900-2010. Environmental Science \& Technology, 47(12), 6400-6407. https://doi.org/10.1021/es400181m

Legeay, P.-L., \& Gruau, G. (2014). Spatio-temporal analysis of phosphorus fluxes and sources in Breton rivers, Trans-P project.

Lemercier, B., Gaudin, L., Walter, C., Aurousseau, P., Arrouays, D., Schvartz, C., et al. (2008). Soil phosphorus monitoring at the regional level by means of a soil test database. Soil Use and Management, 24(2), 131-138. https://doi.org/10.1111/j.1475-2743.2008.00146.x

Lloyd, C. E. M., Freer, J. E., Collins, A. L., Johnes, P. J., \& Jones, J. I. (2014). Methods for detecting change in hydrochemical time series in response to targeted pollutant mitigation in river catchments. Journal of Hydrology, 514, 297-312. https://doi.org/10.1016/j. jhydrol.2014.04.036 
Melland, A. R., Fenton, O., \& Jordan, P. (2018). Effects of agricultural land management changes on surface water quality: A review of meso-scale catchment research. Environmental Science and Policy, 84, 19-25. https://doi.org/10.1016/j.envsci.2018.02.011

Mellander, P.-E., Jordan, P., Bechmann, M., Fovet, O., Shore, M. M., McDonald, N. T., \& Gascuel-Odoux, C. (2018). Integrated climate-chemical indicators of diffuse pollution from land to water. Scientific Reports, 8(1), 944. https://doi.org/10.1038/s41598-018-19143-1

Minaudo, C., Dupas, R., Gascuel-Odoux, C., Fovet, O., Mellander, P. E., Jordan, P., et al. (2017). Nonlinear empirical modeling to estimate phosphorus exports using continuous records of turbidity and discharge. Water Resources Research, 53, 7590-7606. https://doi.org/ 10.1002/2017WR020590

Minaudo, C., Meybeck, M., Moatar, F., Gassama, N., \& Curie, F. (2015). Eutrophication mitigation in rivers: 30 years of trends in spatial and seasonal patterns of biogeochemistry of the Loire River (1980-2012). Biogeosciences, 12(8), 2549-2563. https://doi.org/10.5194/ bg-12-2549-2015

Molenat, J., Gascuel-Odoux, C., Ruiz, L., \& Gruau, G. (2008). Role of water table dynamics on stream nitrate export and concentration in agricultural headwater catchment (France). Journal of Hydrology, 348(3-4), 363-378. https://doi.org/10.1016/j.jhydrol.2007.10.005

Mulholland, P. J., Helton, A. M., Poole, G. C., Hall, R. O., Hamilton, S. K., Peterson, B. J., et al. (2008). Stream denitrification across biomes and its response to anthropogenic nitrate loading. Nature, 452(7184), 202-205. https://doi.org/10.1038/nature06686

Musolff, A., Fleckenstein, J. H., Rao, P. S. C., \& Jawitz, J. W. (2017). Emergent archetype patterns of coupled hydrologic and biogeochemical responses in catchments. Geophysical Research Letters, 44, 4143-4151. https://doi.org/10.1002/2017GL072630

Musolff, A., Schmidt, C., Rode, M., Lischeid, G., Weise, S. M., \& Fleckenstein, J. H. (2016). Groundwater head controls nitrate export from an agricultural lowland catchment. Advances in Water Resources, 96, 95-107. https://doi.org/10.1016/j.advwatres.2016.07.003

Neal, C., Jarvie, H. P., Withers, P. J. A., Whitton, B. A., \& Neal, M. (2010). The strategic significance of wastewater sources to pollutant phosphorus levels in English rivers and to environmental management for rural, agricultural and urban catchments. Science of the Total Environment, 408(7), 1485-1500. https://doi.org/10.1016/j.scitotenv.2009.12.020

Outram, F. N., Cooper, R. J., Sünnenberg, G., Hiscock, K. M., \& Lovett, A. A. (2016). Antecedent conditions, hydrological connectivity and anthropogenic inputs: Factors affecting nitrate and phosphorus transfers to agricultural headwater streams. Science of the Total Environment, 545-546, 184-199. https://doi.org/10.1016/j.scitotenv.2015.12.025

Pinay, G., Gascuel-Odoux, C., Ménesguen, A., Souchon, Y., LeMoal, M., Levain, A., et al. (2017). Eutrophication: Manifestations, causes, consequences and predictability, Joint Scientific Appraisal, Report, CNRS - Ifremer - INRA - Irstea (France), pp. 136.

Pinay, G., Peiffer, S., De Dreuzy, J. R., Krause, S., Hannah, D. M., Fleckenstein, J. H., et al. (2015). Upscaling nitrogen removal capacity from local hotspots to low stream Orders' drainage basins. Ecosystems, 18(6), 1101-1120. https://doi.org/10.1007/s10021-015-9878-5

Poisvert, C., Curie, F., \& Moatar, F. (2017). Annual agricultural N surplus in France over a 70-year period. Nutrient Cycling in Agroecosystems, 107(1), 63-78. https://doi.org/10.1007/s10705-016-9814-x

Rode, M., Halbedel, S., Anis, M., Borchardt, D., \& Weitere, M. (2016). Continuous in-stream assimilatory nitrate uptake from high frequency sensor measurements. Environmental Science \& Technology, 50(11), 5685-5694. https://doi.org/10.1021/acs.est.6b00943

Romero, E., Le Gendre, R., Garnier, J., Billen, G., Fisson, C., Silvestre, M., \& Riou, P. (2016). Long-term water quality in the lower seine: Lessons learned over 4 decades of monitoring. Environmental Science \& Policy, 58, 141-154. https://doi.org/10.1016/j.envsci.2016.01.016

Sardans, J., Rivas-Ubach, A., \& Penuelas, J. (2012). The elemental stoichiometry of aquatic and terrestrial ecosystems and its relationships with organismic lifestyle and ecosystem structure and function: A review and perspectives. Biogeochemistry, 111(1-3), 1-39. https://doi.org/ $10.1007 /$ s10533-011-9640-9

Seitzinger, S. P., Mayorga, E., Bouwman, A. F., Kroeze, C., Beusen, A. H. W., Billen, G., et al. (2010). Global river nutrient export: A scenario analysis of past and future trends. Global Biogeochemical Cycles, 24, GB0A08. https://doi.org/10.1029/2009GB003587

Sen, P. K. (1968). Estimates of the regression coefficient based on Kendall's tau. Journal of the American Statistical Association, 63(324), 1379-1389. https://doi.org/10.1080/01621459.1968.10480934

Steffen, W., Richardson, K., Rockstrom, J., Cornell, S. E., Fetzer, I., Bennett, E. M., et al. (2015). Planetary boundaries: Guiding human development on a changing planet. Science, 347(6223), 1259855. https://doi.org/10.1126/science.1259855

Stets, E. G., Kelly, V. J., \& Crawford, C. G. (2015). Regional and temporal differences in nitrate trends discerned from long-term water quality monitoring data. Journal of the American Water Resources Association, 51(5), 1394-1407. https://doi.org/10.1111/1752 1688.12321

Team, R. D. C. T. (2008). R: A Language and Environment for Statistical Computing. Vienna, Austria: R Foundation for Statistical Computing.

Van Meter, K. J., \& Basu, N. B. (2017). Time lags in watershed-scale nutrient transport: An exploration of dominant controls. Environmental Research Letters, 12(8), 084017. https://doi.org/10.1088/1748-9326/aa7bf4

Van Meter, K. J., Basu, N. B., \& Van Cappellen, P. (2017). Two centuries of nitrogen dynamics: Legacy sources and sinks in the Mississippi and Susquehanna River basins. Global Biogeochemical Cycles, 31, 2-23. https://doi.org/10.1002/2016GB005498

Verbesselt, J., Hyndman, R., Newnham, G., \& Culvenor, D. (2010). Detecting trend and seasonal changes in satellite image time series. Remote Sensing of Environment, 114(1), 106-115. https://doi.org/10.1016/j.rse.2009.08.014

Vero, S. E., Basu, N. B., Van Meter, K., Richards, K. G., Mellander, P. E., Healy, M. G., \& Fenton, O. (2017). Review: The environmental status and implications of the nitrate time lag in Europe and North America. Hydrogeology Journal, 26(1), 7-22.

Viaroli, P., Soana, E., Pecora, S., Laini, A., Naldi, M., Fano, E. A., \& Nizzoli, D. (2018). Space and time variations of watershed N and P budgets and their relationships with reactive $\mathrm{N}$ and $\mathrm{P}$ loadings in a heavily impacted river basin (Po River, northern Italy). Science of the Total Environment, 639, 1574-1587. https://doi.org/10.1016/j.scitotenv.2018.05.233

Wall, D. P., Murphy, P. N. C., Melland, A. R., Mechan, S., Shine, O., Buckley, C., et al. (2012). Evaluating nutrient source regulations at different scales in five agricultural catchments. Environmental Science \& Policy, 24, 34-43. https://doi.org/10.1016/j.envsci.2012.06.007

Withers, P. J. A., Jordan, P., May, L., Jarvie, H. P., \& Deal, N. E. (2014). Do septic tank systems pose a hidden threat to water quality? Frontiers in Ecology and the Environment, 12(2), 123-130. https://doi.org/10.1890/130131

Worrall, F., Howden, N. J. K., \& Burt, T. P. (2015). Time series analysis of the world's longest fluvial nitrate record: Evidence for changing states of catchment saturation. Hydrological Processes, 29(3), 434-444. https://doi.org/10.1002/hyp.10164

Worrall, F., Jarvie, H. P., Howden, N. J. K., \& Burt, T. P. (2016). The fluvial flux of total reactive and total phosphorus from the UK in the context of a national phosphorus budget: Comparing UK river fluxes with phosphorus trade imports and exports. Biogeochemistry, 130(1-2), 31-51. https://doi.org/10.1007/s10533-016-0238-0

Zeileis, A., \& Grothendieck, G. (2005). Zoo: S3 infrastructure for regular and irregular time series. Journal of Statistical Software, 14(6), 1-27. 